\title{
COMMENTARY
}

\section{Target blood pressure in sepsis: between a rock and a hard place}

\author{
François Beloncle', Nicolas Lerolle', Peter Radermacher ${ }^{2}$ and Pierre Asfar*1 \\ See related research by Corrêa et al., http://ccforum.com/content/17/1/R21
}

\begin{abstract}
The optimal target blood pressure in septic shock is still unknown. Therefore, in a long-term, resuscitated porcine model of fecal peritonitis-induced septic shock, Corrêa and colleagues tested whether different titrations of mean arterial pressure (50 to 60 and 75 to $85 \mathrm{~mm} \mathrm{Hg}$ ) would produce different effects on sepsisrelated organ dysfunction. The higher blood pressure window was associated with increased needs for fluid resuscitation and norepinephrine support. However, titrating the lower blood pressure range coincided with an increased incidence of acute kidney injury. In contrast, neither the inflammatory response nor tissue mitochondrial activity showed any difference. This research paper in a clinically relevant model elegantly demonstrates that any standard resuscitation strategy may be a double-edged sword with respect to various therapeutic endpoints. Furthermore, it adds an important piece to the puzzle of the complex pathophysiology of sepsis-related acute kidney injury.
\end{abstract}

In the previous issue of Critical Care, Corrêa and colleagues [1] reported on the effects of different target blood pressures during long-term, resuscitated porcine septic shock. Twelve hours after induction of peritonitis by inoculation of autologous feces into the abdominal cavity, animals were randomly assigned to a control group without resuscitation or to treatment groups with resuscitation with crystalloid and colloid fluids together with norepinephrine targeting a mean arterial pressure (MAP) of either 50 to $60 \mathrm{~mm} \mathrm{Hg}$ ('low-MAP') or 75 to $85 \mathrm{~mm} \mathrm{Hg}$ ('high-MAP'). Whereas all control animals

\footnotetext{
*Correspondence: piasfar@chu-angers.fr
}

'Département de Réanimation Médicale et de Médecine Hyperbare, Centre Hospitalier Universitaire Angers, Laboratoire de Biologie Neurovasculaire et Mitochondriale Intégrée, CNRS UMR 6214 - INSERM U1083 Angers, PRES I'UNAM, Université d'Angers, 4 rue Larrey, F-49 933 Angers Cedex 9, France

Full list of author information is available at the end of the article died within the first 30 hours, 7 out of 8 animals survived in each treatment group at 48 hours after induction of sepsis. The high-MAP group had higher requirements for fluid and, particularly, norepinephrine, whereas lowMAP animals presented with a higher incidence of acute kidney injury (AKI).

Although MAP is a cornerstone of the hemodynamic management of patients with septic shock, its optimal target value is still unknown. Clearly, prolonged phases of hypotension (MAP of less than $60 \mathrm{~mm} \mathrm{Hg}$ ) are associated with increased mortality [2,3], and early goal-directed therapy-related improved survival coincided with a higher MAP [4]. Nevertheless, an upper threshold has not been identified: increasing MAP to greater than $70 \mathrm{~mm} \mathrm{Hg}$ at the expense of a higher vasopressor load coincided with increased mortality in a retrospective analysis [5]. However, in various prospective trials, no signs of excessive vasoconstriction were detected, although MAP values were frequently higher than recommended targets $[6,7]$. Moreover, the prospective studies investigating the effects of MAP increments (from 60 to $90 \mathrm{~mm} \mathrm{Hg}$ ) on various outcomes, including renal function, studied only small numbers of already hemodynamically stabilized patients (10 and 28 patients) over short periods of time (105 minutes and 4 hours per MAP level) and reported no changes in kidney function $[8,9]$.

What do we learn from the study by Corrêa and colleagues? First of all, the authors have to be commended for using an experimental design that nicely fulfills the criteria of a clinically relevant model, namely (a) lacking resuscitation led to $100 \%$ mortality, (b) treatment began 12 hours after the initial aggression, and (c) included antibiotics, protocol-guided mechanical ventilation, fluid resuscitation, and vasopressor treatment. Clearly, the higher incidence of AKI in the low-MAP group agrees well with observational data in patients: Dünser and colleagues [3] observed a direct relation between plasma creatinine and the 'hourly blood pressure time integral', and Badin and colleagues [10] reported decreased AKI at 72 hours with a MAP of at least $72 \mathrm{~mm} \mathrm{Hg}$, when septic shock patients already had AKI at 6 hours after inclusion in the study. Hence, although long-term renal effects of 
higher MAP remain unknown, the low MAP-related kidney dysfunction is an important finding, particularly given the strong association between AKI and poor outcome [11].

Nevertheless, the study cannot definitely answer the question of the optimal target MAP in septic shock. As in most experimental models, the pigs studied were young and 'healthy' before the experiment, which is not the case for adult patients admitted for septic shock in intensive care units. Consequently, the optimal MAP derived from such experiments may differ markedly from the level needed in old patients with comorbidities. Clinical settings require a more subtle balance, especially in patients with arterial hypertension or chronic kidney disease or both. It is well known that, in non-septic conditions, hypertension-related histological changes in the small arteries of the kidney alter renal autoregulation. The renal autoregulatory threshold (that is, the threshold MAP, below which renal blood flow becomes directly related to perfusion pressure) is higher in spontaneously hypertensive rats than in healthy controls [12]. Moreover, during sepsis, little is known about the renal autoregulatory threshold, and, finally, we must keep in mind that autoregulatory thresholds may differ between organs [13]. Any beneficial effect of high MAP on the kidney may coincide with harmful effects in other organs with lower autoregulatory threshold (for example, the brain and heart).

What is the 'take home message' on the relation between blood pressure and sepsis-induced kidney dysfunction? Clearly, Corrêa and colleagues demonstrated that low-MAP levels were associated with a higher incidence of AKI, even under conditions of a sustained increase in cardiac output. However, the link between MAP level and kidney function is probably more complex than usually considered. On the one hand, Di Giantomasso and colleagues [14] reported that renal failure occurred in hypotensive ewes with sepsis despite increased kidney blood flow. On the other hand, Benes and colleagues [15] elegantly showed that AKI developed in septic pigs despite well-maintained hyperdynamic and normotensive hemodynamics and that this was most likely because of systemic inflammation and oxidative stress. Of note, in that study, MAP was close to the values of the high-MAP group in the present study.

Furthermore, although this study was not designed to answer this question, Corrêa and colleagues raised the issue of the specific effect of norepinephrine. The consequences of the systemic effect of norepinephrine (that is, maintaining an elevated MAP level) cannot be distinguished from its specific intrarenal effect (that is, similar vasoconstrictive action on both afferent and efferent arterioles) [16]. Moreover, this study does not address the question of whether higher MAP level (or higher norepinephrine doses) could also decrease histological injury severity or only improve renal function.

Finally, even in the low-MAP group, severity of shock was moderate (lactate levels did not increase in comparison with baseline, and the arterial base excess decreased to approximately 1 to $2 \mathrm{mmol} / \mathrm{L}$ ), and only 1 out of 8 animals developed AKI stage 2 (increase in blood creatinine between 2 and 3 times). Unfortunately, as the authors do not report plasma protein or total hemoglobin content, any dilution effect of the higher amount of fluid resuscitation on creatinine concentrations could not be assessed in the high-MAP group. The lacking hemoglobin data leave the reader with another open question: according to the protocol, dobutamine was infused if the mixed venous oxygen saturation $\left(\mathrm{SvO}_{2}\right)$ was less than $50 \%$. Strikingly, baseline $\mathrm{SvO}_{2}$ values were only $48 \%$ and $50 \%$ in the two treatment arms, respectively, despite a stroke volume within the normal range. Thus, a contribution of pre-existing anemia cannot be excluded.

In conclusion, this elegant study adds an important brick in the wall. It nicely demonstrates that early hemodynamic intervention on MAP may attenuate the occurrence of AKI solely by increasing renal perfusion pressure. The direct translation to clinical practice is difficult because of the limitations acknowledged by the authors. In patients with septic shock, the SEPSISPAM trial (ClinicalTrial.gov NCT01149278), which has completed recruitment, will most likely answer some of the questions raised by the study by Corrêa and colleagues.

\section{Abbreviations}

$\mathrm{AKI}$, acute kidney injury; MAP, mean arterial pressure; $\mathrm{SvO}_{2}$, mixed venous oxygen saturation.

\section{Competing interests}

PA is the principal investigator of a completed, investigator-led, multicenter randomized controlled trial assessing the target blood pressure in sepsis (SEPSISPAM trial), but he declares that this is a non-financial competing interest. The other authors declare that they have no competing interests.

\section{Acknowledgments}

FB was supported by a grant from the Délégation Interrégionale à la Recherche Clinique des Hopitaux Universitaires du Grand Ouest (DiRC HUGO) PR was supported by the Deutsche Forschungsgemeinschaft (Klinische Forschergruppe 200 ,Die Entzündungsantwort nach Muskulo-Skeletalem Trauma').

\section{Author details}

'Département de Réanimation Médicale et de Médecine Hyperbare, Centre Hospitalier Universitaire Angers, Laboratoire de Biologie Neurovasculaire et Mitochondriale Intégrée, CNRS UMR 6214 - INSERM U1083 Angers, PRES I'UNAM, Université d'Angers, 4 rue Larrey, F-49 933 Angers Cedex 9, France. 2Sektion Anästhesiologische Pathophysiologie und Verfahrensentwicklung, Klinik für Anästhesiologie, Universitätsklinikum, Helmholtzstrasse 8-1, 89081, Ulm, Germany.

Published: 26 March 2013

\section{References}

1. Corrêa TD, Vuda M, Takala J, Djafarzadeh S, Silva E, Jakob SM: Increasing mean arterial blood pressure in sepsis: effects on fluid balance, vasopressor load and renal function. Crit Care 2013, 17:R21. 
2. Varpula M, Tallgren M, Saukkonen K, Voipio-Pulkki L-M, Pettilä V: Hemodynamic variables related to outcome in septic shock. Intensive Care Med 2005, 31:1066-1071.

3. Dünser MW, Takala J, Ulmer H, Mayr VD, Luckner G, Jochberger S, Daudel F, Lepper P, Hasibeder WR, Jakob SM: Arterial blood pressure during early sepsis and outcome. Intensive Care Med 2009, 35:1225-1233.

4. Rivers E, Nguyen B, Havstad S, Ressler J, Muzzin A, Knoblich B, Peterson E, Tomlanovich M: Early goal-directed therapy in the treatment of severe sepsis and septic shock. N Engl J Med 2001, 345:1368-1377.

5. Dünser MW, Ruokonen E, Pettilä V, Ulmer H, Torgersen C, Schmittinger CA, Jakob S, Takala J: Association of arterial blood pressure and vasopressor load with septic shock mortality: a post hoc analysis of a multicenter trial. Crit Care 2009, 13:R181.

6. López A, Lorente JA, Steingrub J, Bakker J, McLuckie A, Willatts S, Brockway M, Anzueto A, Holzapfel L, Breen D, Silverman MS, Takala J, Donaldson J, Arneson C, Grove G, Grossman S, Grover R: Multiple-center, randomized, placebocontrolled, double-blind study of the nitric oxide synthase inhibitor 546C88: effect on survival in patients with septic shock. Crit Care Med 2004, 32:21-30

7. Russell JA, Walley KR, Singer J, Gordon AC, Hébert PC, Cooper DJ, Holmes CL, Mehta S, Granton JT, Storms MM, Cook DJ, Presneill JJ, Ayers D: Vasopressin versus norepinephrine infusion in patients with septic shock. N Engl J Med 2008, 358:877-887.

8. LeDoux D, Astiz ME, Carpati CM, Rackow EC: Effects of perfusion pressure on tissue perfusion in septic shock. Crit Care Med 2000, 28:2729-2732.

9. Bourgoin A, Leone M, Delmas A, Garnier F, Albanèse J, Martin C: Increasing mean arterial pressure in patients with septic shock: effects on oxygen variables and renal function. Crit Care Med 2005, 33:780-786.
10. Badin J, Boulain T, Ehrmann S, Skarzynski M, Bretagnol A, Buret J, BenzekriLefevre D, Mercier E, Runge I, Garot D, Mathonnet A, Dequin P-F, Perrotin D: Relation between mean arterial pressure and renal function in the early phase of shock: a prospective, explorative cohort study. Crit Care 2011, 15:R135.

11. Bagshaw SM, Uchino S, Bellomo R, Morimatsu H, Morgera S, Schetz M, Tan I, Bouman C, Macedo E, Gibney N, Tolwani A, Oudemans-van Straaten HM, Ronco C, Kellum JA: Septic acute kidney injury in critically ill patients: clinical characteristics and outcomes. Clin J Am Soc Nephrol 2007, 2:431-439.

12. Iversen BM, Sekse I, Ofstad J: Resetting of renal blood flow autoregulation in spontaneously hypertensive rats. Am J Physiol 1987, 252:F480-486.

13. Johnson PC: Autoregulation of blood flow. Circ Res 1986, 59:483-495

14. Di Giantomasso D, May CN, Bellomo R: Vital organ blood flow during hyperdynamic sepsis. Chest 2003, 124:1053-1059.

15. Benes J, Chvojka J, Sykora R, Radej J, Krouzecky A, Novak I, Matejovic M: Searching for mechanisms that matter in early septic acute kidney injury: an experimental study. Crit Care 2011, 15:R256.

16. Edwards RM: Segmental effects of norepinephrine and angiotensin II on isolated renal microvessels. Am J Physiol 1983, 244:F526-534

doi:10.1186/cc12543

Cite this article as: Beloncle F, et al: Target blood pressure in sepsis: between a rock and a hard place. Critical Care 2013, 17:126. 